Paper ID 5141

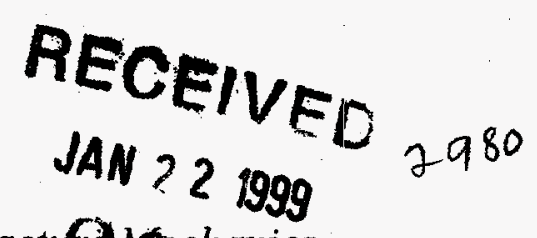

Prepared for the 30th National Symposium on Fatigue and Fractuglgethanics,
Washington University, St. Louis, Missouri, June 23-25, 1998

\title{
TECHNICAL BASIS FOR THE MASTER CURVE CONCEPT OF FRACTURE TOUGHNESS EVALUATIONS IN THE TRANSITION RANGE*
}

\author{
D. E. McCabe, J. G. Merkle, $\dagger$ and K. Wallin $\ddagger$ \\ Metals and Ceramics Division \\ OAK RIDGE NATIONAL LABORATORY \\ Oak Ridge, TN 37831-6151
}

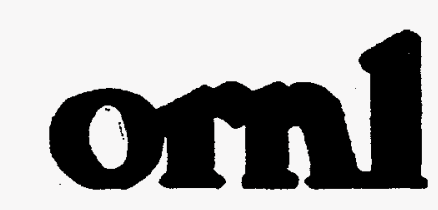

\footnotetext{
${ }^{*}$ Research sponsored by the Division of Engineering Technology, Office of Nuclear Regulatory Research, U.S. Nuclear Regulatory Commission, under Interagency Agreement DOE 1886-N011-9B with the U.S. Department of Energy under Contract No. DE-AC05-960R22464 with Lockheed Martin Energy Research Corporation.
}

†Engineering Technology Division.

$\ddagger$ Technical Research Centre of Finland, P.O. Box 1700, Kemistintie 3, Espoo, FIN-02044, Finland.

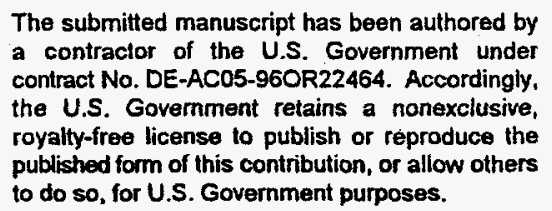




\section{DISCLAIMER}

This report was prepared as an account of work sponsored by an agency of the United States Government. Neither the United States Government nor any agency thereof, nor any of their employees, make any warranty, express or implied, or assumes any legal liability or responsibility for the accuracy, completeness, or usefulness of any information, apparatus, product, or process disclosed, or represents that its use would not infringe privately owned rights. Reference herein to any specific commercial product, process, or service by trade name, trademark, manufacturer, or otherwise does not necessarily constitute or imply its endorsement, recommendation, or favoring by the United States Government or any agency thereof. The views and opinions of authors expressed herein do not necessarily state or reflect those of the United States Government or any agency thereof. 


\section{DISCLAIMER}

Portions of this document may be illegible in electronic image products. Images are produced from the best available original document. 
Donald E. McCabe, ${ }^{1}$ John G. Merkle, ${ }^{2}$ and Kim Wallin ${ }^{3}$

TECHNICAL BASIS FOR THE MASTER CURVE CONCEPT OF FRACTURE TOUGHNESS EVALUATIONS IN THE TRANSITION RANGE

REFERENCE: McCabe, D. E., Merkle, J. G., and Wallin, K., "Technical Basis for the Master Curve Concept of Fracture Toughness Evaluations in the Transition Range," Fatigue and Fracture Mechanics, 30th Volume, ASTM STP 1360, P. C. Paris and K. L. Jerina, Eds., American Society for Testing and Materials, 1999.

ABSTRACT: An American Society for Testing and Materials (ASTM) standard method (E 1921-97) has been developed that exclusively uses fracture mechanics test practices and advanced statistical methods to establish the ductile-to-brittle transition range of fracture toughness for structural steels. The development of suitably accurate analyses had been slowed in the past due to an incomplete understanding of the operational mechanisms that control the fracture toughness behavior of structural steels. New perspectives taken are (1) that dominant linear-elastic conditions need not be rigidly enforced in test specimens and (2) that the effect of specimen size on fracture toughness performance is mostly controlled by a weakest-link

${ }^{1}$ Metals and Ceramics Division, Oak Ridge National Laboratory, Oak Ridge, TN 37831-5151.

${ }^{2}$ Engineering Technology Division, Oak Ridge National Laboratory, Oak Ridge, TN 37831-8049.

${ }^{3}$ Technical Research Centre of Finland, P.O. Box 1700, Kemistinte 3, Espoo, FIN-02044, Finland. 
mechanism instead of being completely controlled by crack tip constraint conditions. The weakest-link behavior is defined from local cleavage crack initiators such as precipitates, inclusions, and grain boundary embrittlement; namely, all microstructural features in steel. Statistical models can be built upon such mechanisms that result in defined fracture probability levels and, when coupled to a master curve concept, can more accurately define the true location of the ductile-to-brittle transition temperature.

An integral part of the ASTM test standard development work has been the production of a supporting technical basis document. This document presents substantial background data and supporting theoretical aspects that have been used to justify the method development. The paper will include some of the salient features presented.

KEYWORDS: $T_{0}$, master curve, ASTM Standard E 1921, transition range, toughness, Weibull, pressure vessel steels

\section{INTRODUCTION}

The fracture toughness property that is of most relevance to structural steel applications is the location of the ductile-to-brittle transition temperature. The empirical test results that have been used for many years to identify this temperature are test method-specific and are of uncertain relevance to in-service conditions for a sharp crack embedded in a dominant elastic stress field and loaded under semi-static conditions. Only fracture mechanics-based test methods are capable 
of such simulations. However, to simulate service conditions, linear elastic analyses will suffice and such conditions are usually associated with the ASTM $\mathrm{K}_{\mathrm{Ic}}$ test practice $\mathrm{E} 399$ [I]. It is also necessary to test within the transition range where $\mathrm{K}_{\mathrm{Ic}}$ validity conditions can only be satisfied with huge specimens that are beyond routine laboratory practice capabilities [2]. A special American Society of Mechanical Engineers (ASME) task group had found a temporary resolution in the early 1970s that has been used on pressure vessel steels [3]. Namely, a substantial collection of $\mathrm{E} 399$ valid $\mathrm{K}_{\mathrm{Ic}}$ data were obtained from a variety of sources and plotted against normalized temperature. All data were referenced to a nil-ductility temperature ( $\left.R T_{N D T}\right)$ (based on empirical test results) and then plotted, perhaps expecting all of the data to lie on a generic lower-bound curve. The result was considerable data scatter, so instead, an approximate statistical method applied was to draw a lower-bound curve to the data scatter and postulate that this curve will never be appreciably violated by data for past or future production of pressure vessel steels. From this standpoint, the lower-bound $\mathrm{K}_{\mathrm{Ic}}$ curve has been regarded as a universal curve and, surprisingly, it has remained in use despite its limitations, for more than 25 years. Most prominent among these weaknesses is the uncertainty associated with empirically derived test temperatures, $\mathrm{RT}_{\mathrm{NDT}}$. Hence, the uncertainty in fracture analyses due to not knowing the correct transition temperature had not been eliminated.

This paper describes a new fracture mechanics-based methodology for transition range toughness definition [4]. The technology incorporates advanced statistical methods to model generic data scatter characteristics of steels. Elastic-plastic fracture toughness evaluation methods are used and the linear elastic-based constraint requirements are abandoned in favor of a weakest-link model to define the specimen size effects that have been observed experimentally 
[5]. The concept that fracture mechanics data tend to follow a universal curve shape is retained, except that, in this case, the concept of a universal curve is fully justified both theoretically and experimentally. ASTM test method E 1921-97 [6] uses these new concepts, and the background information developed in support of the standard has been prepared in a U.S. Nuclear Regulatory Commission NUREG report, Technical Basis for an ASTM Standard on Determining the Reference Temperature, $T_{\infty}$ for Ferritic Steels in the Transition Range. Temperature, $\mathrm{T}_{0}$, is used as a reference temperature in a similar way as $\mathrm{RT}_{\mathrm{NDT}}$ has been used, except that it is developed entirely from fracture mechanics data and it is based upon median toughness instead of a lower-bound curve, as has been the case for the $\operatorname{ASME~} \mathrm{K}_{\mathrm{Ic}}$ curve.

\section{MANAGING DATA SCATTER}

The new viewpoint is that the scatter of fracture mechanics-type data is recognized as being an omnipresent characteristic of structural steels. The concept to be presented in the following sections acknowledges that data scatter results from randomly distributed cleavage triggering sources such as carbide cracking, multiple cleavage crack clustering, and dislocation pile-ups. The theoretical basis for data distributions uses weakest-link theory coupled to a Poisson distribution assumption for cleavage crack triggering as follows:

$$
P_{f}=1-\exp (-\rho V)
$$


The exponential term in Eq. (1) is the probability of finding no critical cleavage sources in volume $V$ when there are $\rho$ critical particles per unit volume. $P_{f}$ represents the cumulative probability of failure.

In the present case, attention is given to volume elements that are local to the crack tip where the highest stresses are concentrated. The active volume for cleavage crack sources scales according to $\left(B / B_{0}\right) K_{I}^{4}[7]$. $B$ is a crack front length and $B_{0}$ is an arbitrarily definable dimension. Other elements that define the critical volume are recognized as being fixed values. Hence, the fundamental result from applying weakest-link theory is:

$$
P_{f}=1-\exp \left[-\frac{B}{B_{0}}\left(\frac{K_{I}}{K_{0}}\right)^{4}\right]
$$

Two deficiencies of Eq. (2) that do not model the true characteristics of steel are (1) that there can be some fraction of cleavage trigger sources that have weak crack drive energy that will arrest, and (2) steels do not approach zero fracture toughness as suggested by the equation. Hence, the statistical model was modified via introduction of the hazard function that resolves both deficiencies mentioned. The model that emerges from these analyses as the most practical is:

$$
\mathrm{P}_{\mathrm{f}}=1-\exp \left[-\left(\frac{\mathrm{B}}{\mathrm{B}_{\mathrm{o}}}\right)\left(\frac{\mathrm{K}_{\mathrm{Jc}}-\mathrm{K}_{\min }}{\mathrm{K}_{\mathrm{o}}-\mathrm{K}_{\min }}\right)^{4}\right]
$$


$\mathrm{K}_{\min }$ is the toughness level below which cleavage cracks cannot propagate. $\mathrm{K}_{0}$ is a scale parameter identified at a point where $\mathrm{K}_{\mathrm{Jc}}=\mathrm{K}_{\mathrm{o}}$ and $\mathrm{P}_{\mathrm{f}}=0.632$. Equation (3) can be utilized to set up a convenient size effect relationship. By setting $P_{f}$ equal for two specimen sizes, where $B=B_{1}$ or $\mathrm{B}=\mathrm{B}_{2}$, the following relationship results:

$$
K_{J c(2)}=\left(K_{J c(1)}-K_{\min }\right)\left(\frac{B_{1}}{B_{2}}\right)^{1 / 4}+K_{\min } .
$$

Equation (4) suggests that specimen size has a rather subtle effect on fracture toughness distributions and this appears to be quite apparent from the experimental evidence that has been obtained [5]. Hence, size effects can only be demonstrated with ample replications at each size level. On the other hand, the various constraint-based models that have been suggested usually indicate more pronounced size effects that are generally not well supported experimentally [5]. The important benefit from the abandonment of absolute constraint control theories is the recognition that elastic-plastic methods can be utilized to the extent that specimens of reasonable sizes can be applied to the development of plant-specific fracture mechanics data. Fracture toughness at the point of crack instability can be calculated in units of J-integral, $\mathrm{J}_{\mathrm{c}}$, and these values are then converted into their equivalence in units of stress intensity factor, $\mathrm{K}_{\mathrm{Jc}}$, given by:

$$
\mathrm{K}_{\mathrm{Jc}}=\sqrt{\mathrm{J}_{\mathrm{c}} \mathrm{E}} .
$$




\section{SMALL SAMPLE STATISTICS}

Equation (3) is the statistical model that has been found to be the most suitable for fitting fracture mechanics-based data. At first, all three parameters, namely, Weibull slope, (b), scale parameter, $\left(\mathrm{K}_{\mathrm{o}}\right)$, and lower bound, $\left(\mathrm{K}_{\min }\right)$, were best fitted to individual data sets [8]. Data replication needs for accurate characterization of data distributions were unappreciated at that time. Also, in the early stages, an application of this methodology for the establishment of a fracture mechanics-based transition curve using fracture mechanics-based reference temperatures had not been considered. The tools needed to apply the statistical approach were developed later [9] and have since served as a justification for the development of an ASTM standard method. The concept was made practical for general use after it was found through a sensitivity study using Monte Carlo techniques that $\mathrm{K}_{\mathrm{Jc}}$ data populations for a variety of steels tend to have a common Weibull slope of approximately 4 and when lower-bound $\mathrm{K}_{\min }$ values are set to $20 \mathrm{MPa} \sqrt{\mathrm{m}}$. These results compared favorably with available experimental data found in the literature (Fig. 1). This study also made it abundantly clear that extremely large data samplings, on the order of 50 or more specimens, must be used to develop sufficient measurement accuracy on slope, $b$, and minimum toughness, $\mathrm{K}_{\min }$, in the Weibull model, Eq. (3). As has been previously discussed, the rationale for this characteristic of $\mathrm{K}_{\mathrm{Jc}}$ data distributions has since been justified in theory.

Experimental evidence for the ASTM test method justification has been found in the form of data taken from a Materials Properties Council/Japan Society for the Promotion of Science (MPC/JSPS) round-robin activity [10] [see Table 1, Part I(a)]. Eighteen participating laboratories 
had tested about 150 specimens divided between three test temperatures, $-50,-75$, and $-100^{\circ} \mathrm{C}$. The test material was A 508 class 3 pressure vessel steel, and 1T compact specimens had been taken from the $1 / 4$ and $3 / 4$ through-thickness locations in the plate. Sample size (replication) for each participant was five specimens. Figure 1 suggests that for a sample size of 5 , Weibull slopes, $b$, obtained by least-squares fitting have a $95 \%$ probability of being between 2 and 12 . Only 1 of 28 experimental slope determinations was outside of these bounds. These same data, after combining into three test temperature groups to develop sample sizes of about 50 specimens, were analyzed for slopes (see the "Total" rows). All three groups tend to converge to a slope of four. Since two of the three Weibull parameters are declared to be deterministic parameters of the model, only the number of specimens needed to determine $\mathrm{K}_{\mathrm{o}}$ remained to be determined from experimental data. Monte Carlo methods were again employed to settle upon sample size requirements. Data populations (nominal groups of 50) were represented by data from the MPC/JSPS round-robin activity. Sample sizes ranged from 3 to 20 in the simulation, as is indicated in the first column of Table 2. Each sampling was repeated 100 times and standard deviation on $\mathrm{K}_{\mathrm{Jc(med)}}$ values are also presented. Clearly, sample sizes on the order of 20 specimens provide the optimum accuracy, but, at the same time, this is obviously not a practical number to recommend for general use. Standard deviation among repeated tests always seemed to plateau between 6 and 8 replications. Such numbers represent a more practical recommendation for standardization purposes. However, it is accepted that error potential accompanies such replication. For a 6 to 8 specimen sampling, there is about $10 \%$ probability that there will be more than $10^{\circ} \mathrm{C}$ error in true transition temperature identification [1I]. To compensate, a recommendation is made to apply margin adjustments to $T_{0}$ temperature determinations when the acknowledged error potential is not acceptable in a specific application. It should be noted at this 
point that there is a fixed relationship between $\mathrm{K}_{\mathrm{o}}$ and $\mathrm{K}_{\mathrm{Jc}(\mathrm{med})}$ so that the required sample size is the same for either parameter.

$$
\mathrm{K}_{\mathrm{Jc}(\text { med })}-20=\left(\mathrm{K}_{\mathrm{o}}-20\right)[\ln 2]^{1 / 4} \mathrm{MPa} \sqrt{\mathrm{m}}
$$

\section{CONCEPT OF MASTER CURVE}

The title of E 1921-97 suggests that the main objective is to determine a reference temperature, $\mathrm{T}_{0}$. This temperature is used to set up a master curve and here is where advanced statistical methods can be used to an advantage. Improved definition of transition range curve shape is the principal benefit. The following master curve equation applies to median toughness obtained from $1 \mathrm{~T}$ specimens or for $\mathrm{K}_{\mathrm{Ic}}$ data from specimens of other sizes converted to $1 \mathrm{~T}$ equivalence (1T size means that specimen thickness $\mathrm{B}=1 \mathrm{in}$.).

$$
\mathrm{K}_{\mathrm{Jc}(\mathrm{med})}=30+70 \exp \left[0.019\left(\mathrm{~T}-\mathrm{T}_{0}\right)\right] \mathrm{MPa} \sqrt{\mathrm{m}}
$$

Equation (7) expresses the median $\mathrm{K}_{\mathrm{Jc}}$ as a function of temperature for data scatter modeled by Eq. (3). Figure 2 shows an example of data sampling taken at eight test temperatures. The experiment used two weld metals identified as $72 \mathrm{~W}$ and $73 \mathrm{~W}$ and two conditions evaluated were in the as-received and as-irradiated conditions at $1.5 \times 10^{19} \mathrm{n} / \mathrm{cm}^{2}(>1 \mathrm{MeV})$ fluence. Figure 3 shows data reduced to median values. All data clearly follow the shape of the master curve. This 
master curve model has been tested on at least 14 different groups of data consisting mostly of pressure vessel steels [4].

\section{DETERMINATION OF REFERENCE TEMPERATURE, $T_{0}$}

There are two options available to fit experimental data to the three-parameter Weibull model. The method that was first recommended in early drafts of E 1921-97 is known as a "rank method," where $K_{\mathrm{Jc}}$ data are ranked according to increased values and then each value is assigned a rank cumulative failure probability value obtained from the following expression [6]:

$$
\left(\mathrm{P}_{\mathrm{f}}\right)_{\mathrm{i}}=(\mathrm{i}-0.3) /(\mathrm{N}+0.4) \text {. }
$$

These data are then plotted in Weibull $x-y$ coordinates, as shown in Fig. 4. Then a line with a fixed slope of 4 is lest-squares fitted to the data.

The rank method mentioned above has been replaced (in the more recent versions of the standard) in favor of the maximum likelihood method of data fitting. The weakness of the rank method is that values of $P_{f}$ obtained from Eq. (8) also have a probability distribution that can contribute some to the uncertainty of $\mathrm{K}_{\mathrm{o}}$ determinations. In fact, Eq. (8) is simply one of several available estimator expressions for $P_{f}$. Figure 5 illustrates estimating uncertainties by showing the $95 \%$ confidence limits on $\mathrm{P}_{\mathrm{f}}$ as a function of $\mathrm{K}_{\mathrm{Jc}}$ for different sample sizes. As indicated, the accuracy of $P_{f}$ estimation by Eq. (8) is a function of sample size. There apparently is no 
satisfactory alternative since Eq. (8) is known to be the most accurate among the several available estimator equations [4].

The maximum likelihood method [4] minimizes the error due to the $P_{f}$ estimate contribution. The point of maximum likelihood on the $\mathrm{P}_{\mathrm{f}}$ density function is solved in terms of likelihood slope, $\delta \mathrm{L} / \delta \mathrm{K}_{0}$; the derivation of which is covered in Ref. [4]. The result is that $\mathrm{K}_{0}$ is determined without the necessity of ranking data and least-squares fitting to the Weibull slope of 4. The solution for $\mathrm{K}_{\mathrm{o}}$ takes the following form:

$$
\mathrm{K}_{\mathrm{o}}=\left[\sum_{\mathrm{i}=1}^{\mathrm{N}} \frac{\left(\mathrm{K}_{\mathrm{Jc}}-\mathrm{K}_{\min }\right)^{4}}{(\mathrm{~N}-\varsigma)}\right]^{1 / 4}+\mathrm{K}_{\min } \mathrm{MPa} \sqrt{\mathrm{m}}
$$

The term $\zeta$ in the denominator of Eq. (9) is a bias adjustment factor, nominally equal to $[1-\ln (2)]$. Bias correction for all intents and purposes becomes insignificant when the number of replicates, N, is six or more. Table 1, Part I(b), presents the use of Eq. (9) on the MPC/JSPS round-robin data.

Data censoring is readily incorporated into Eq. (9) by replacing $\mathrm{N}$ with $\mathrm{r}$, where $\mathrm{r}$ represents the number of valid data. When data are censored, it is because they are deemed to be ineligible members of the data population, the existence of which can be credited as information, but under restrictions. For example, if a $\mathrm{K}_{\mathrm{Jc}}$ value has been determined on a specimen that failed a 
constraint control limit, that datum is censored from the data population and a constraint-limit-based $\mathrm{K}_{\mathrm{Jc}}$ value obtained in the following Eq. (10) is used in its place:

$$
\mathrm{K}_{\mathrm{Jc}(\text { limit })}=\left(\mathrm{Eb}_{\mathrm{o}} \sigma_{\mathrm{ys}} / 30\right)^{1 / 2}
$$

The term $b_{o}$ is the initial remaining ligament length and $\sigma_{y s}$ is the material yield strength. It is required that when data censoring is used in the determination of $\mathrm{K}_{\mathrm{o}}$ that $\mathrm{K}_{\mathrm{Jc}}$ data input be for only one specimen size. Having determined $\mathrm{K}_{\mathrm{o}}$ at the known test temperature, T, Eqs. (6) and (7) can be used to determine reference temperature, $T_{0}$ [see also Table 1, Part I(b)].

\section{ESTABLISHMENT OF TOLERANCE BOUNDS}

Since slope is used as a deterministic parameter in the Weibull model, standard deviation on $\mathrm{K}_{\mathrm{Jc}(\text { med })}$ can be calculated without any need for additional supporting data. The statistical method uses gamma functions that are calculated from the known Weibull slope. Reference [4] shows how this determination is made. The result is:

$$
\sigma=0.28 \mathrm{~K}_{\mathrm{Jc}(\text { med })}\left[1-\frac{\mathrm{K}_{\min }}{\mathrm{K}_{\mathrm{Jc}(\mathrm{med})}}\right]
$$


Given known standard deviations that are a function of $\mathrm{K}_{\mathrm{Jc}(\text { med) }}$, tolerance bound curves on data scatter can be calculated by combining Eqs. (7) and (11) and tabulated standard normal deviates, $\mathrm{z}$, from mathematical tables given for cumulative probabilities. The general form for equations of upper or lower tolerance bound curves is as follows:

$$
\mathrm{K}_{\mathrm{TB}}=(30 \pm 2.8 \mathrm{z})+(70 \pm 19.6 \mathrm{z}) \exp \left[0.019\left(\mathrm{~T}-\mathrm{T}_{\mathrm{o}}\right)\right] \mathrm{MPa} \sqrt{\mathrm{m}}
$$

An interesting outcome from Eq. (12) is that lower tolerance bound curves tend to be almost insensitive to specimen size effects (Fig. 6) [12]. Therefore, tolerance bounds drawn on the master curve with $1 \mathrm{~T}$ specimen size assumption also tend to cover non-size-adjusted $\mathrm{K}_{\mathrm{Jc}}$ data from tests on large specimens.

\section{SOME VERIFICATION OF THE UNIVERSAL CURVE CONCEPT}

Originally, 12 data sets had been used to recognize that $\mathrm{K}_{\mathrm{Jc}}$ data distributions tend to follow a common curve shape (Fig. 7). In this case, scale parameter, $\mathrm{K}_{\mathrm{o}}$, was used. Currently, $\mathrm{K}_{\mathrm{Jc}(\mathrm{med})}$ is used, differing by the proportionality indicated in Eq. (6). Many other materials have since been added to the original observation, covering different grades of ferritic steels, hence, broadening the applicability of the universal curve concept. At the same time, there have been concerns that the rationale for such behavior is not immediately evident. Among these, the retention of master curve shape after irradiation hardening seems to have violated the hypothesis of a consistent relationship between material yield strength and fracture toughness for a given 
material [12]. Several theoretical models that explain transition range fracture toughness have been based on such an assumed relationship. However, Fig. 8 shows the seemingly typical retention of master curve shape after strengthening from irradiation exposure.

It has been shown that material yield strength property appears to consist of thermal and athermal components [4]. The athermal part is connected to certain dislocation slip-constricting effects local to precipitates and grain boundaries. On the other hand, the matrix material in grains will retain unaltered thermally sensitive characteristics and it is this part of the microstructure that controls the transition range fracture toughness trend. Figure 9 shows how the material strength versus temperature relationship is maintained when an athermal component of yield strength is removed. Hence, the lack of material-strengthening mechanisms influencing master curve toughness trend can be explained. Other areas of concern such as strain rate effects, temper embrittlement, low upper-shelf materials, etc., are currently being evaluated.

\section{CONCLUSIONS}

The accuracy of defining the true transition range behavior of structural steels has been improved by the introduction of a new statistically supported methodology. Fracture mechanics test methods are used to establish the true location of the transition curve. The cause of extreme data scatter and the reason for specimen size effects on data are explained by weakest-link theory. Data scatter is modeled and tolerance bounds on data scatter are defined in terms of cumulative probabilities for occurrence. A universal transition curve is defined, the shape of which has been justified by repeated confirmatory experimental evidence. The universal curve concept appears to 
be undisturbed by material hardening mechanisms and the reason for this insensitivity to material hardening mechanisms can be rationalized.

\section{ACKNOWLEDGMENTS}

This research is sponsored by the Division of Engineering Technology, Office of Nuclear Regulatory Research, U.S. Nuclear Regulatory Commission, under Interagency Agreement DOE 1886-N011-9B with the U.S. Department of Energy under Contract DE-AC05-96OR22464 with Lockheed Martin Energy Research Corporation.

\section{REFERENCES}

[1]. ASTM Standard Test Method E 399-90, "Plane-Strain Fracture Toughness of Metallic Materials," Annual Book of ASTM Standards, Vol. 03.01, 1996.

[2]. "PVRC Recommendations on Toughness Requirements for Ferritic Materials," Welding Research Council Bulletin 175, Welding Research Council, New York, New York, August 1972.

[3]. White Paper on Reactor Vessel Integrity Requirements for Level A and B Conditions, EPRI TR-100241, Electric Power Research Institute, Palo Alto, California, January 1993.

[4]. J. G. Merkle, K. Wallin, and D. E. McCabe, Technical Basis for an ASTM Standard on Determining the Reference Temperature, $T_{o}$ for Ferritic Steels in the Transition Range, Draft NUREG, to be published.

[5]. D. E. McCabe, U. Zerbst, and J. Heerens, Development of Test Practice Requirements for 
a Standard Method on Fracture Toughness Testing in the Transition Range, GKSS

Report 93/E/81, GKSS-Forschungszentrum, Geesthacht GmbH, Germany, 1993.

[6]. ASTM Standard Test Method E 1921-97, "Determination of Reference Temperature, $T_{0}$, for Ferritic Steels in the Transition Range," Annual Book of ASTM Standards, Vol. 03.01, 1998.

[7]. D. I. A. Stienstra, Stochastic Micromechanical Modeling of Cleavage Fracture in the Ductile-Brittle Transition Region, MM-6013-90-11, Texas A \& M University, College Station, Texas, 1990.

[8]. J. D. Landes and D. E. McCabe, "Effect of Section Size on Transition Temperature Behavior of Structural Steels," pp. 378-382 in Fracture Mechanics: Fifteenth Symposium, ASTM STP 833, R. J. Sanford, Ed., American Society for Testing and Materials, 1984.

[9]. K. Wallin, "The Scatter in $\mathrm{K}_{\mathrm{Ic}}$ Results," Engineering Fracture Mechanics, 19(6): 1083-1093 (1984).

[10]. W. A. Van Der Sluys and M. T. Miglin, "Results of MPC/JSPS Cooperative Testing Program in the Brittle-to-Ductile Transition Region," pp. 308-324 in Fracture Mechanics: Twenty-Fourth Volume, ASTM STP 1207, American Society for Testing and Materials, 1994.

[1I]. C. A. J. Miranda and J. D. Landes, "Influence of the Number of Specimens in the Reference Temperature Determination: The Monte Carlo Approach," Paper 1401, IPEN/CNEN/SP, 1997 (to be published).

[12]. D. J. Neville and J. F. Knott, "Statistical Distributions of Toughness and Fracture Stress for Homogeneous and Inhomogeneous Materials," J. Mech. Phys. Solids., 34(3), 243-291 
(1986). 
Table 1. Analysis of MPC/JSPS round-robin data

\begin{tabular}{|c|c|c|c|}
\hline \multicolumn{2}{|c|}{ I(a) } & \multicolumn{2}{|c|}{$\mathrm{I}(\mathrm{b})$} \\
\hline Laboratory & $\begin{array}{c}\text { Best } \\
\text { slope }^{\alpha}\end{array}$ & $\begin{array}{c}\mathrm{K}_{\mathrm{o}}{ }^{b} \\
(\mathrm{MPa} \sqrt{ } \mathrm{m})\end{array}$ & $\begin{array}{c}\mathrm{T}_{\mathrm{o}} \\
\left({ }^{\circ} \mathrm{C}\right)\end{array}$ \\
\hline \multicolumn{4}{|c|}{ Test temperature, $-50^{\circ} \mathrm{C}$} \\
\hline B & 3.0 & 294 & -115 \\
\hline C & 4.1 & 284 & -113 \\
\hline E & 2.6 & 241 & -103 \\
\hline $\mathrm{H}$ & 4.3 & 277 & -111 \\
\hline $\mathrm{J}$ & 12.6 & 177 & -83 \\
\hline $\mathrm{O}$ & 1.8 & 205 & -93 \\
\hline $\mathrm{P}$ & 6.0 & 187 & -87 \\
\hline$Q$ & 3.5 & 262 & -108 \\
\hline $\mathrm{R}$ & 3.8 & 233 & -101 \\
\hline Combined data & 3.75 & 250 & -105 \\
\hline \multicolumn{4}{|c|}{ Test temperature, $-75^{\circ} \mathrm{C}$} \\
\hline A & 2.8 & 184 & -111 \\
\hline C & 3.7 & 168 & -105 \\
\hline D & 8.8 & 161 & -103 \\
\hline $\mathrm{H}$ & 5.8 & 156 & -101 \\
\hline $\mathrm{J}$ & 5.5 & 148 & -97 \\
\hline K & 7.1 & 177 & -109 \\
\hline $\mathrm{N}$ & 3.9 & 163 & -104 \\
\hline Q & 5.1 & 192 & -114 \\
\hline $\mathrm{R}$ & 6.5 & 150 & -98 \\
\hline Combined data & 5.8 & 166 & -105 \\
\hline \multicolumn{4}{|c|}{ Test temperature, $-100^{\circ} \mathrm{C}$} \\
\hline A & 5.0 & 118 & -107 \\
\hline $\mathrm{C}$ & 3.0 & 127 & -112 \\
\hline $\mathrm{E}$ & 4.0 & 132 & -114 \\
\hline $\mathrm{F}$ & 5.4 & 120 & -108 \\
\hline G & 5.6 & 109 & -101 \\
\hline $\mathrm{H}$ & 5.1 & 114 & -104 \\
\hline L & 11.3 & 143 & -120 \\
\hline$M$ & 3.4 & 101 & -95 \\
\hline$Q$ & 3.9 & 139 & -118 \\
\hline $\mathbf{R}$ & 2.8 & 114 & -104 \\
\hline Combined data & 4.3 & 123 & -109 \\
\hline $\begin{array}{l}{ }^{\circ} \text { By linear regres } \\
{ }^{b} \text { Maximum likeli }\end{array}$ & 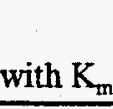 & $a / m$ & \\
\hline
\end{tabular}


Table 2. Monte Carlo simulation

(100 trials; population, $501 \mathrm{~T} \mathrm{C(T)} \mathrm{A} 508$ class 3 specimens; $-75^{\circ} \mathrm{C}$ test temperature)

\begin{tabular}{|c|c|c|c|c|l|}
\hline $\begin{array}{c}\text { Sample } \\
\text { size }\end{array}$ & $\begin{array}{c}\text { Population } \\
\text { size }\end{array}$ & $\begin{array}{c}\text { Number } \\
\text { of trials }\end{array}$ & $\begin{array}{c}\mathrm{K}_{\mathrm{Jc}(\mathrm{med})} \\
(\mathrm{MPa} \sqrt{\mathrm{m}})\end{array}$ & $\begin{array}{c}\text { Standard } \\
\text { deviation } \\
(\mathrm{MPa} \sqrt{\mathrm{m}})\end{array}$ & \multicolumn{1}{|c|}{ Total population } \\
\hline 3 & 50 & 100 & 154.2 & 16.5 & $\mathrm{~K}_{\mathrm{Jc} \text { (med) }}=153 \mathrm{MPa} \sqrt{\mathrm{m}}$ \\
4 & 50 & 100 & 154.4 & 15.0 & $\mathrm{~T}_{\mathrm{o}}=-104^{\circ} \mathrm{C}$ \\
5 & 50 & 100 & 154.5 & 12.5 & \\
6 & 50 & 100 & 153.4 & 11.8 & \\
7 & 50 & 100 & 151.9 & 11.6 & \\
8 & 50 & 100 & 152.2 & 11.1 & \\
9 & 50 & 100 & 153.7 & 9.1 & \\
10 & 50 & 100 & 153.4 & 8.5 & \\
20 & 50 & 100 & 153.1 & 6.1 & \\
\hline
\end{tabular}




\section{FIGURE CAPTIONS}

Fig. 1. Comparison of the distribution of Weibull slopes calculated from small data sets with Monte Carlo predicted confidence limits when $\mathrm{K}_{\min }$ is set at $20 \mathrm{MPa} \vee \mathrm{m}$.

Fig. 2. Example of master curve and data from the HSSI Fifth Irradiation Series.

Fig. 3. Median $\mathrm{K}_{\mathrm{Jc}}$ values plotted against master curve for two weld metals in the unirradiated and irradiated conditions.

Fig. 4. Example $\mathrm{K}_{\mathrm{Jc}}$ data plotted in Weibull coordinates along with a least-squares fitted line with a slope of 4 .

Fig. 5. Reliability of small sample data sets of size $n$, when expressed in cumulative probability coordinates.

Fig. 6. Effect of specimen size on median $\mathrm{K}_{\mathrm{Jc}}$ and tolerance bound trends as predicted by the weakest-link model, established at test temperature equal to $T_{0}$.

Fig. 7. Original data used to develop the master curve equation shown.

Fig. 8. Relation between fracture toughness and temperature for unirradiated and irradiated steel.

Fig. 9. Thermal part of material yield strength after the separation of "athermal" part of yield strength. 


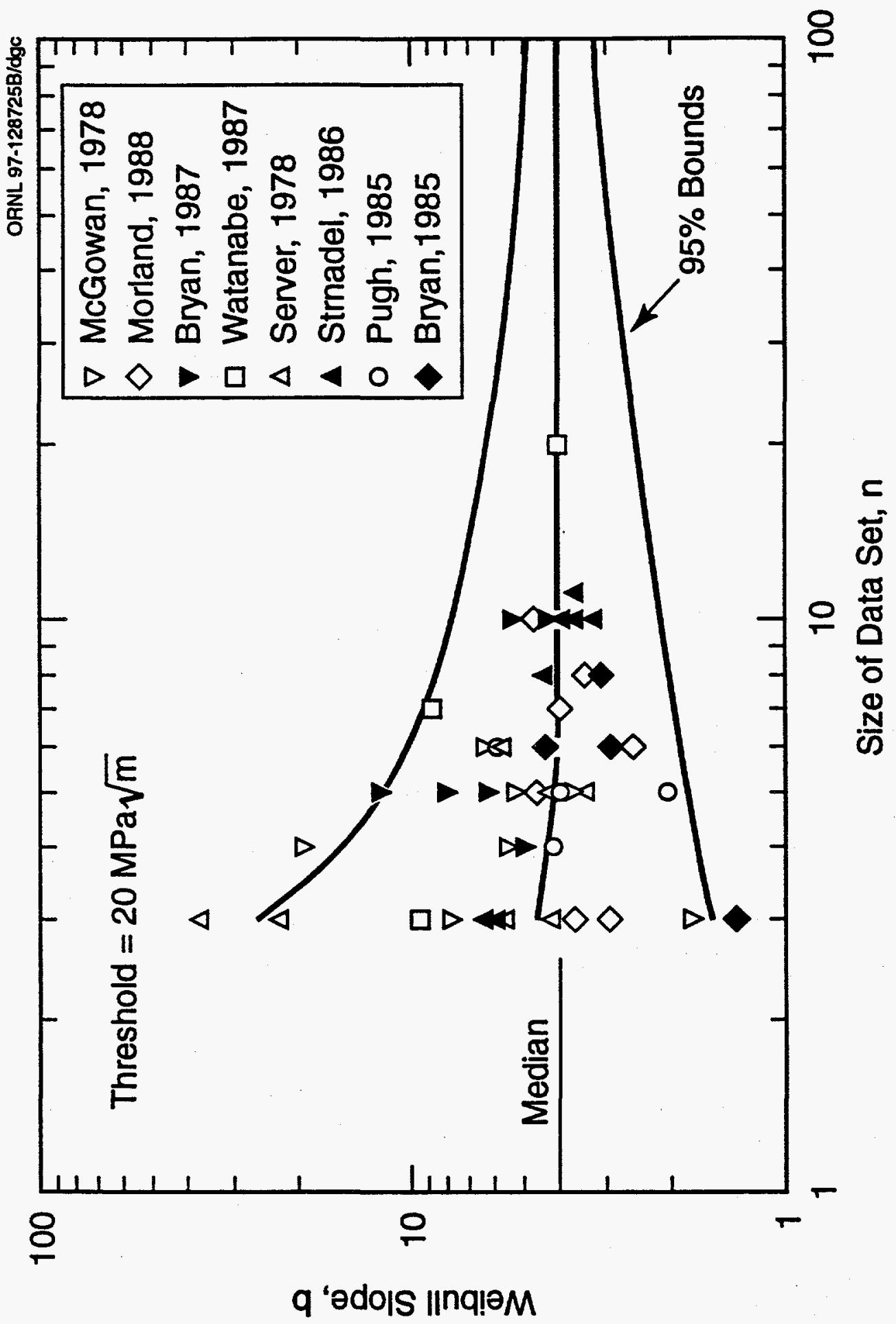




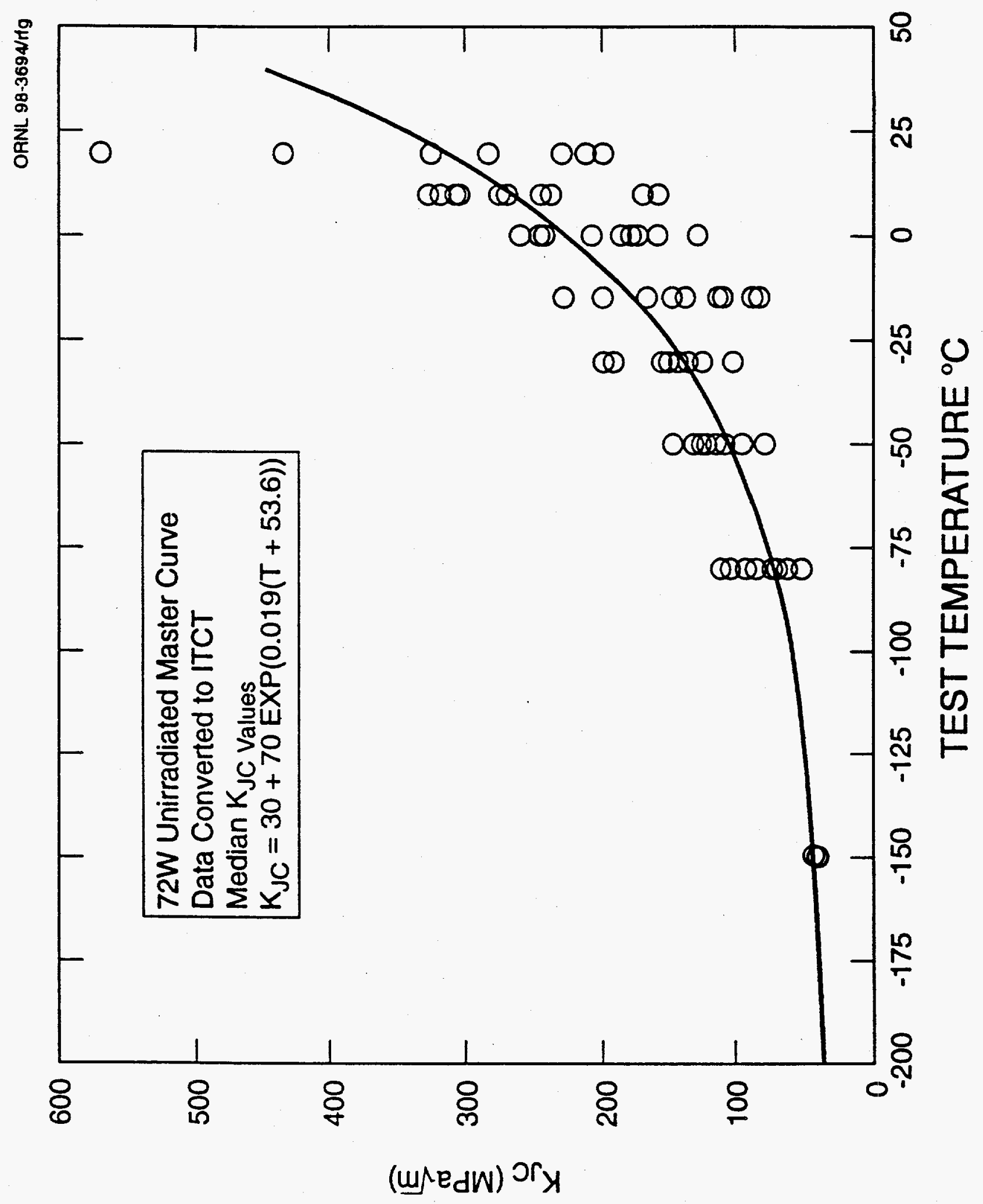




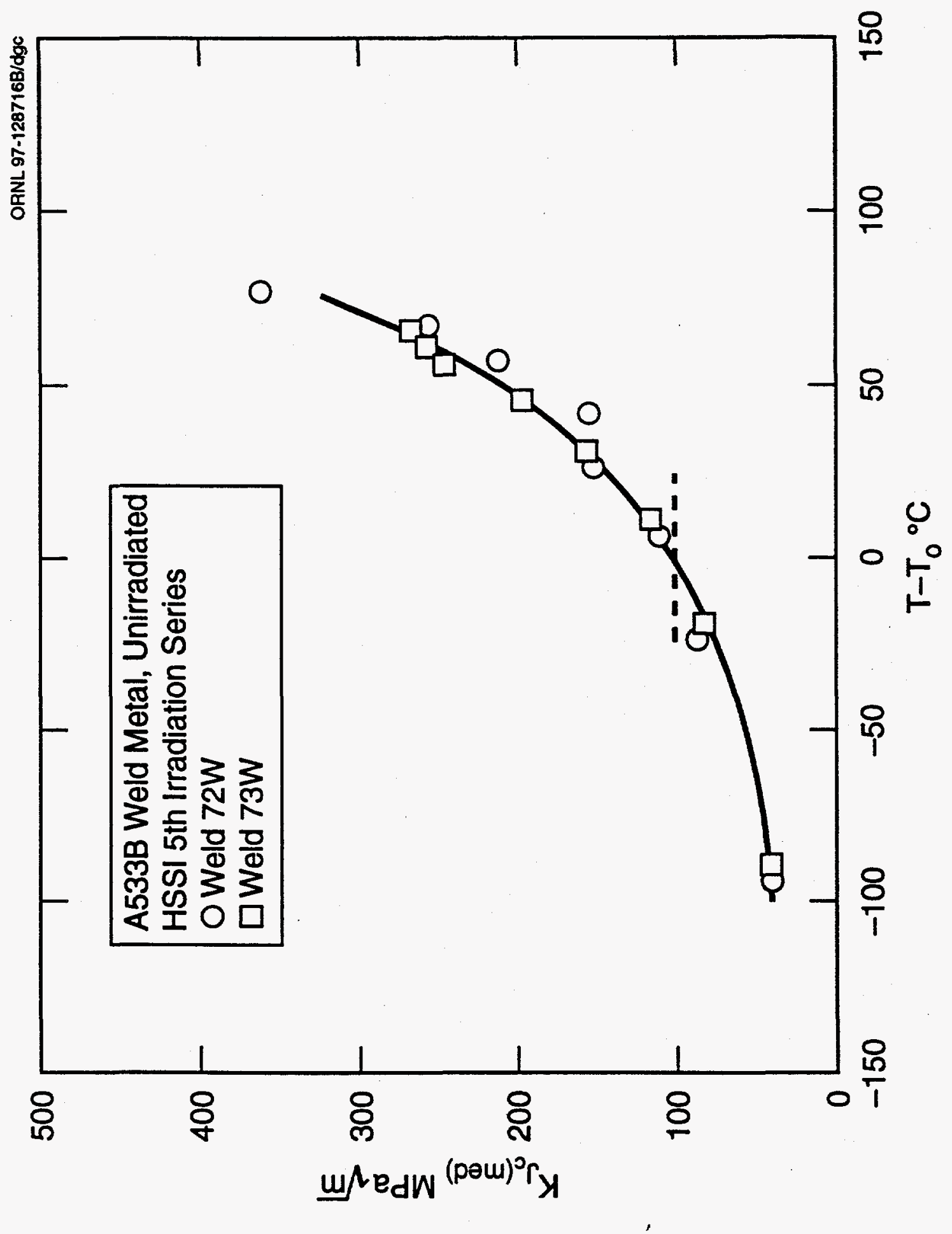




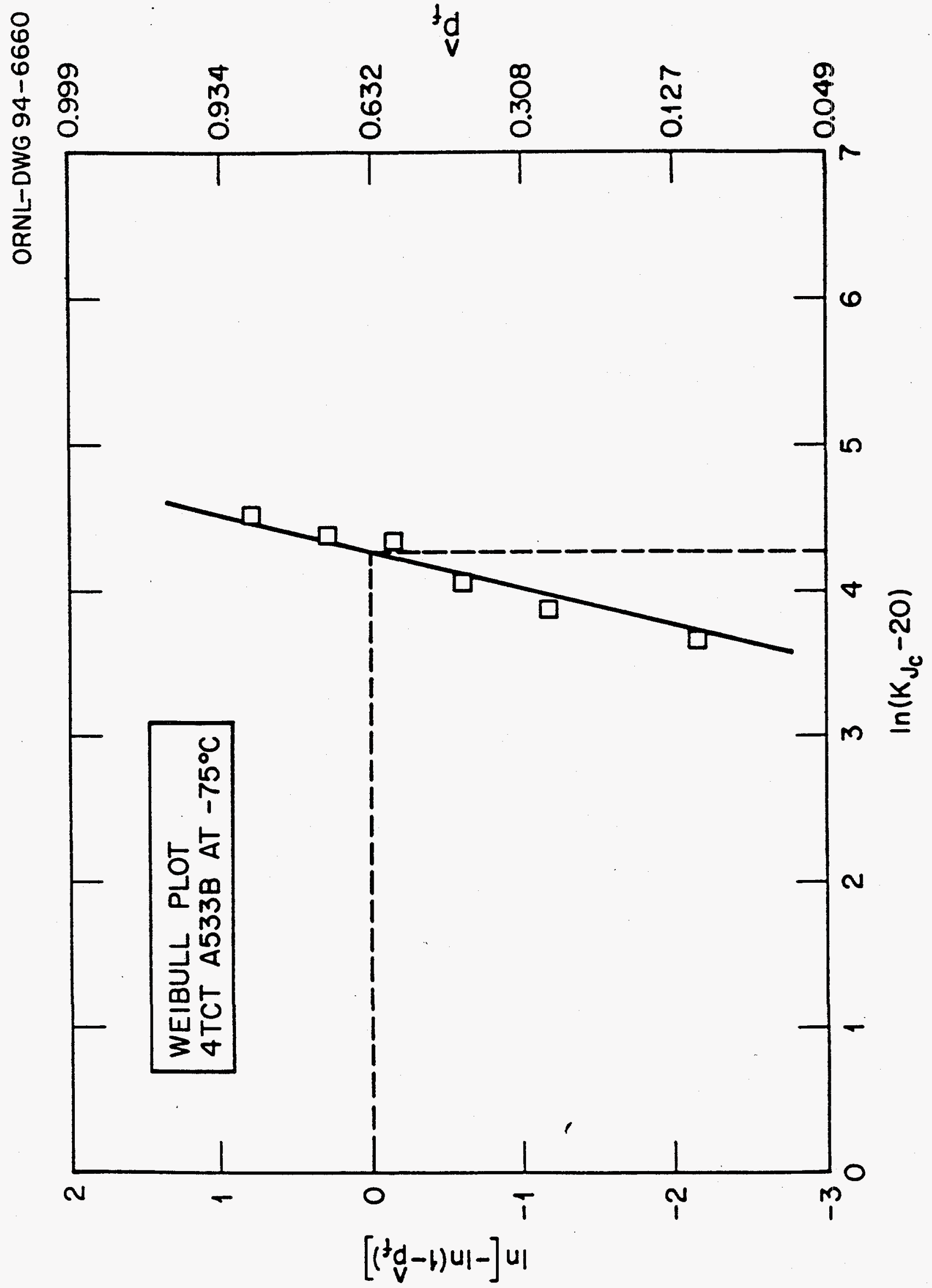




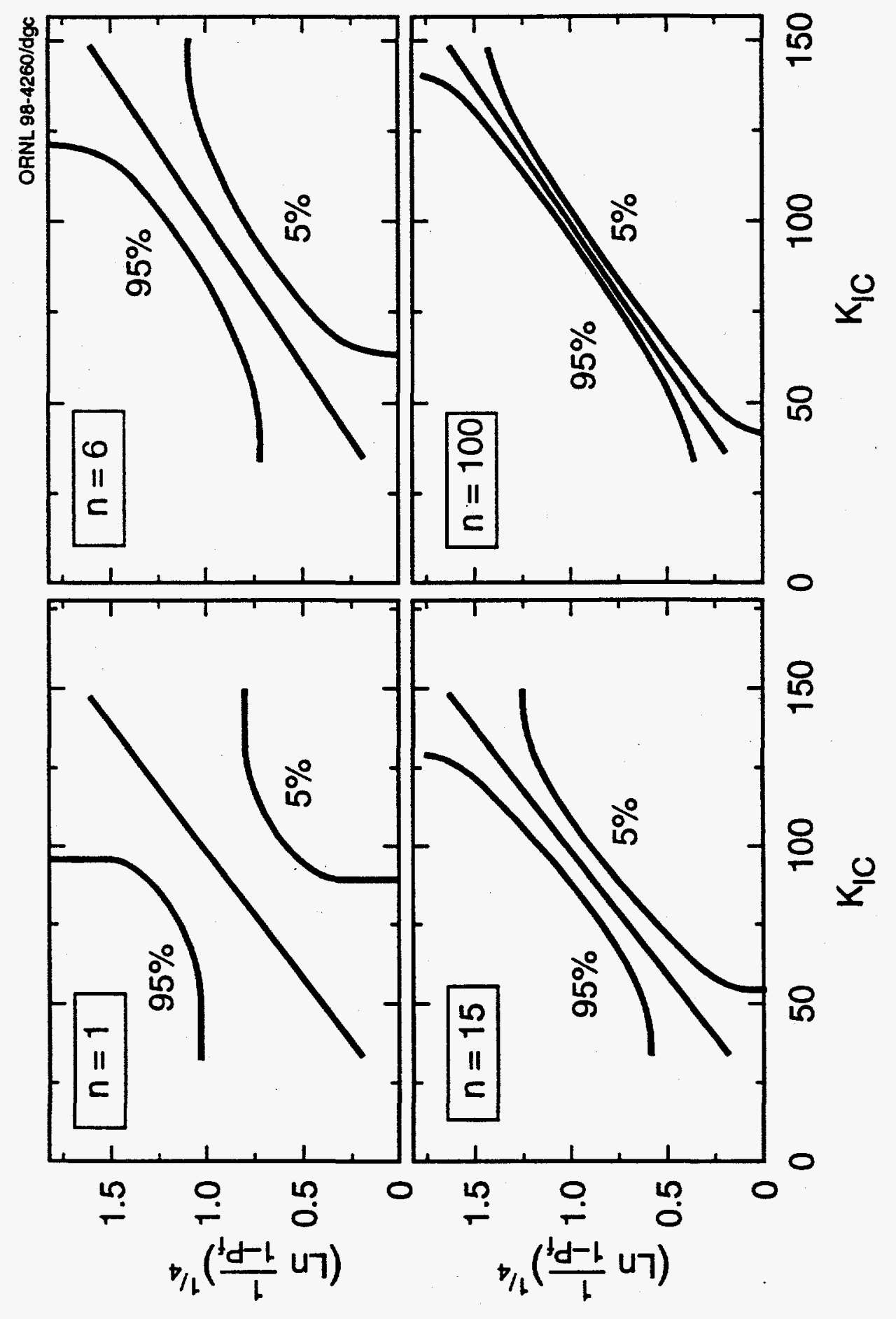

ב⿱⺈ 


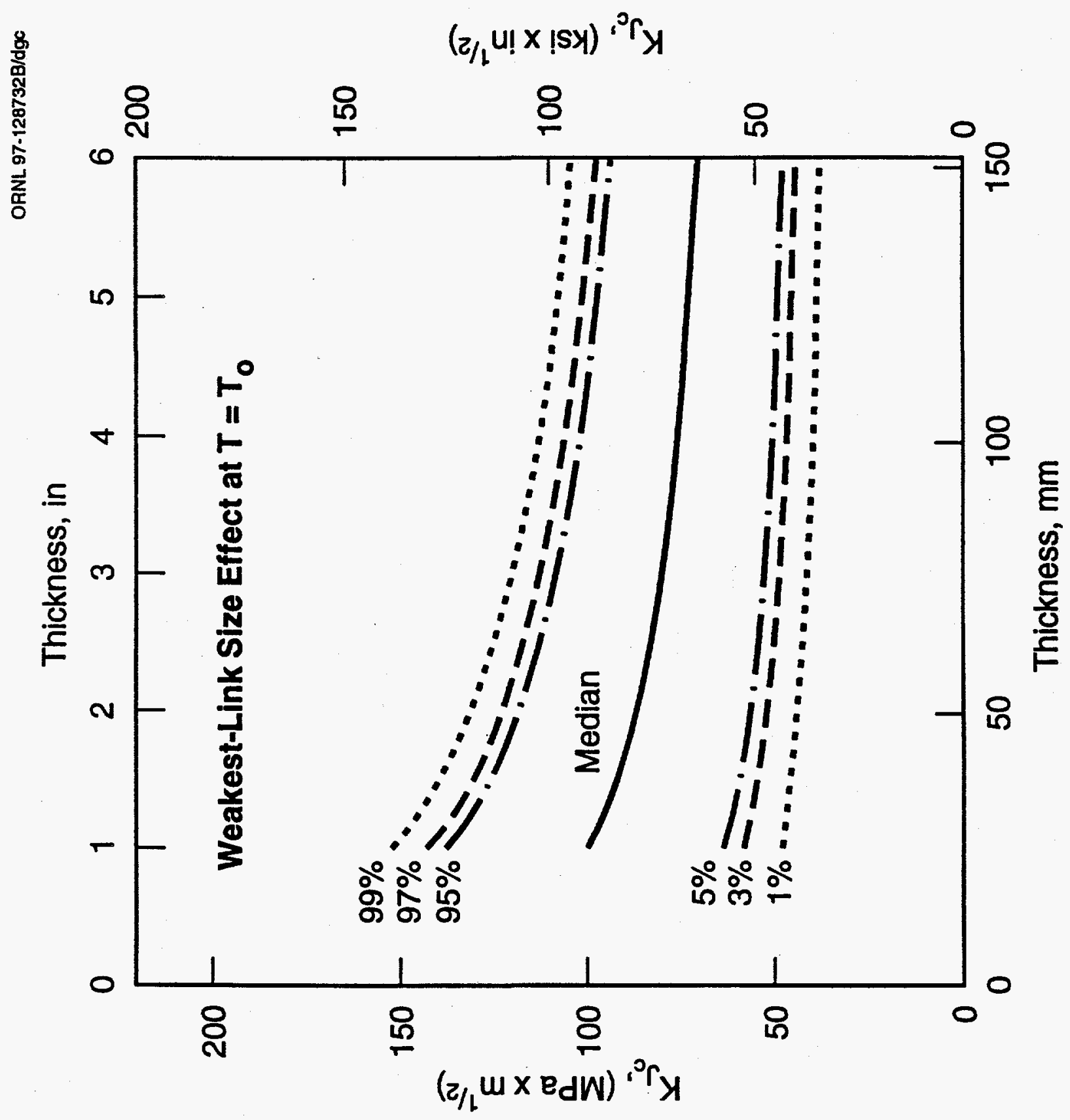




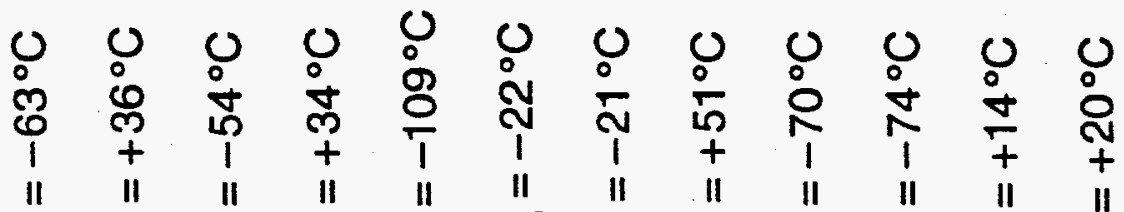

$$
\begin{aligned}
& \vdash \vdash \vdash \vdash \circ
\end{aligned}
$$

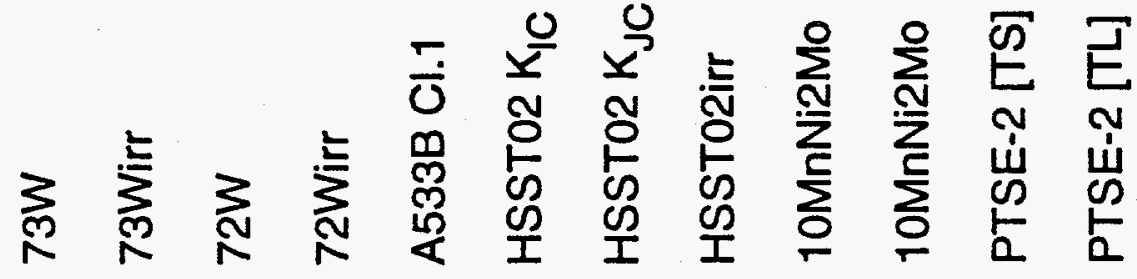

$$
\begin{aligned}
& \circ \bullet \square \square \triangleleft \triangleleft \triangleright>+x \diamond
\end{aligned}
$$

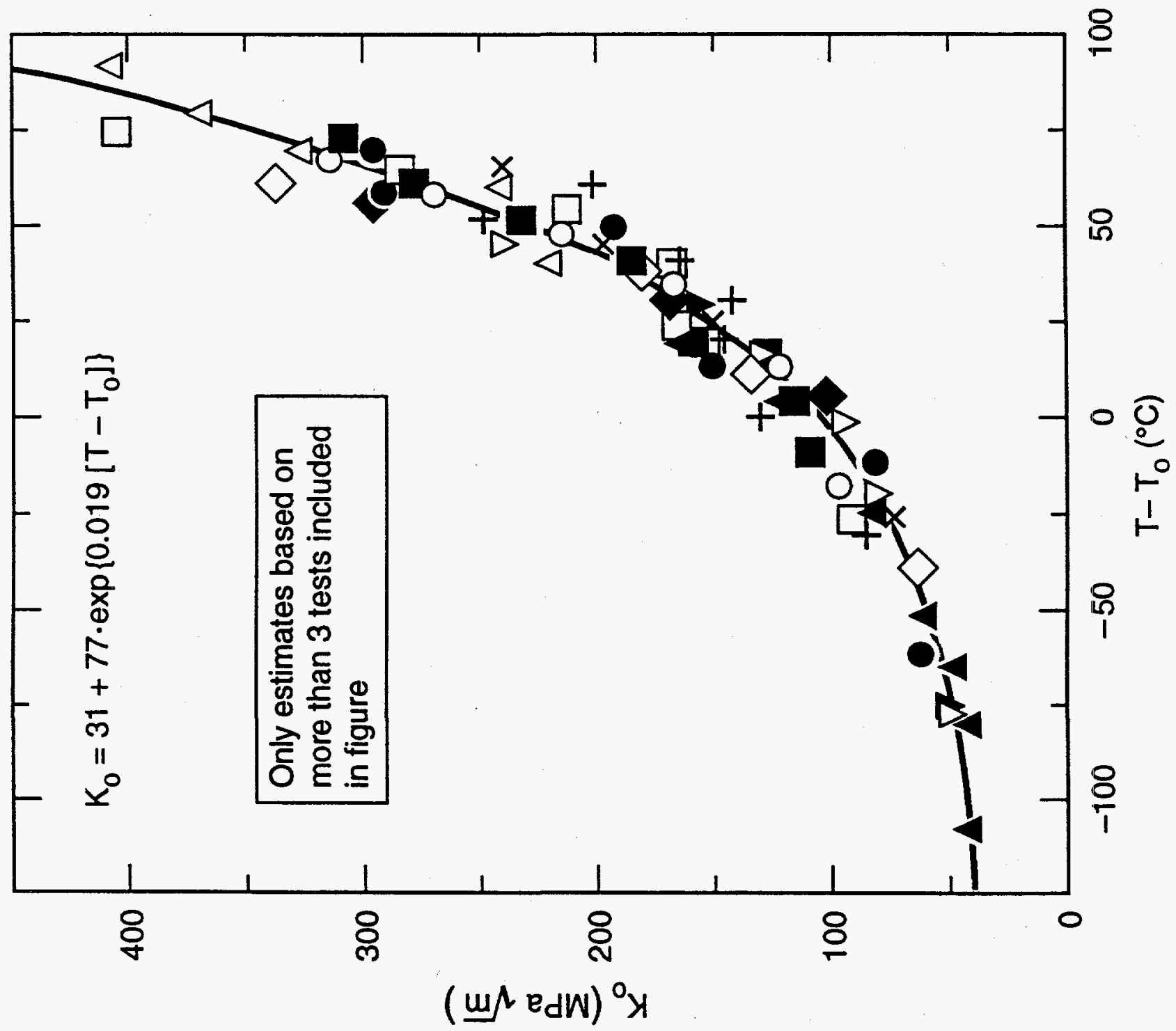




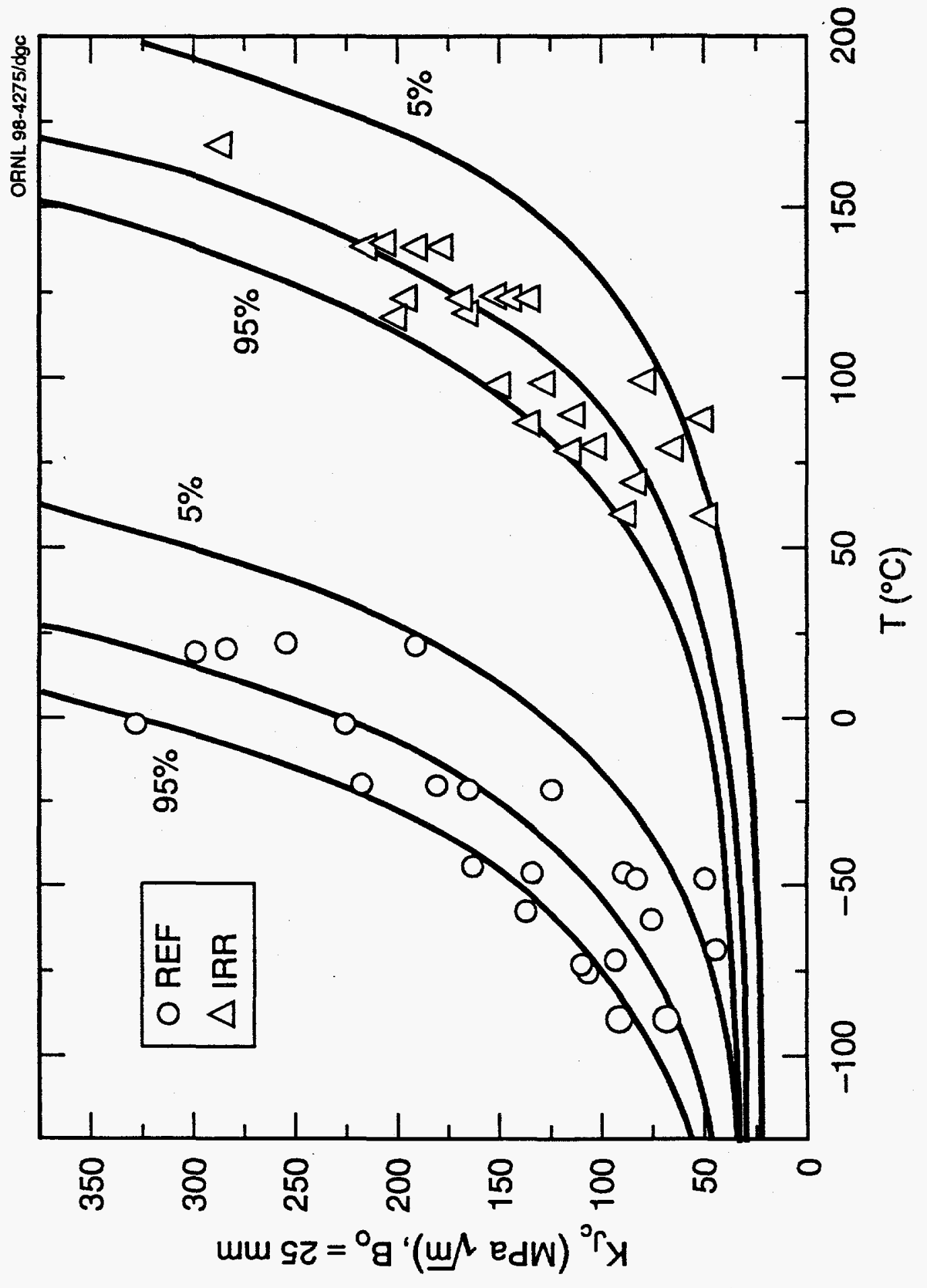




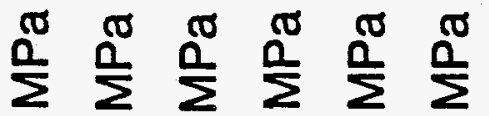

$$
\begin{aligned}
& \text { 年 }
\end{aligned}
$$

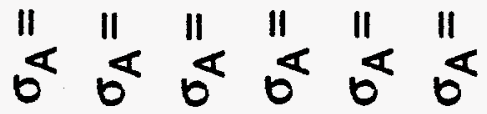

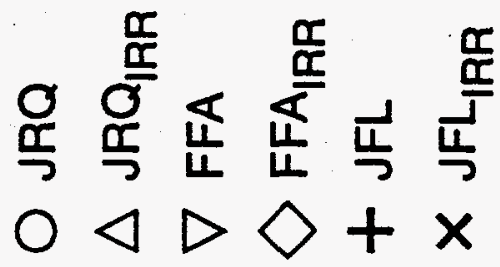

文

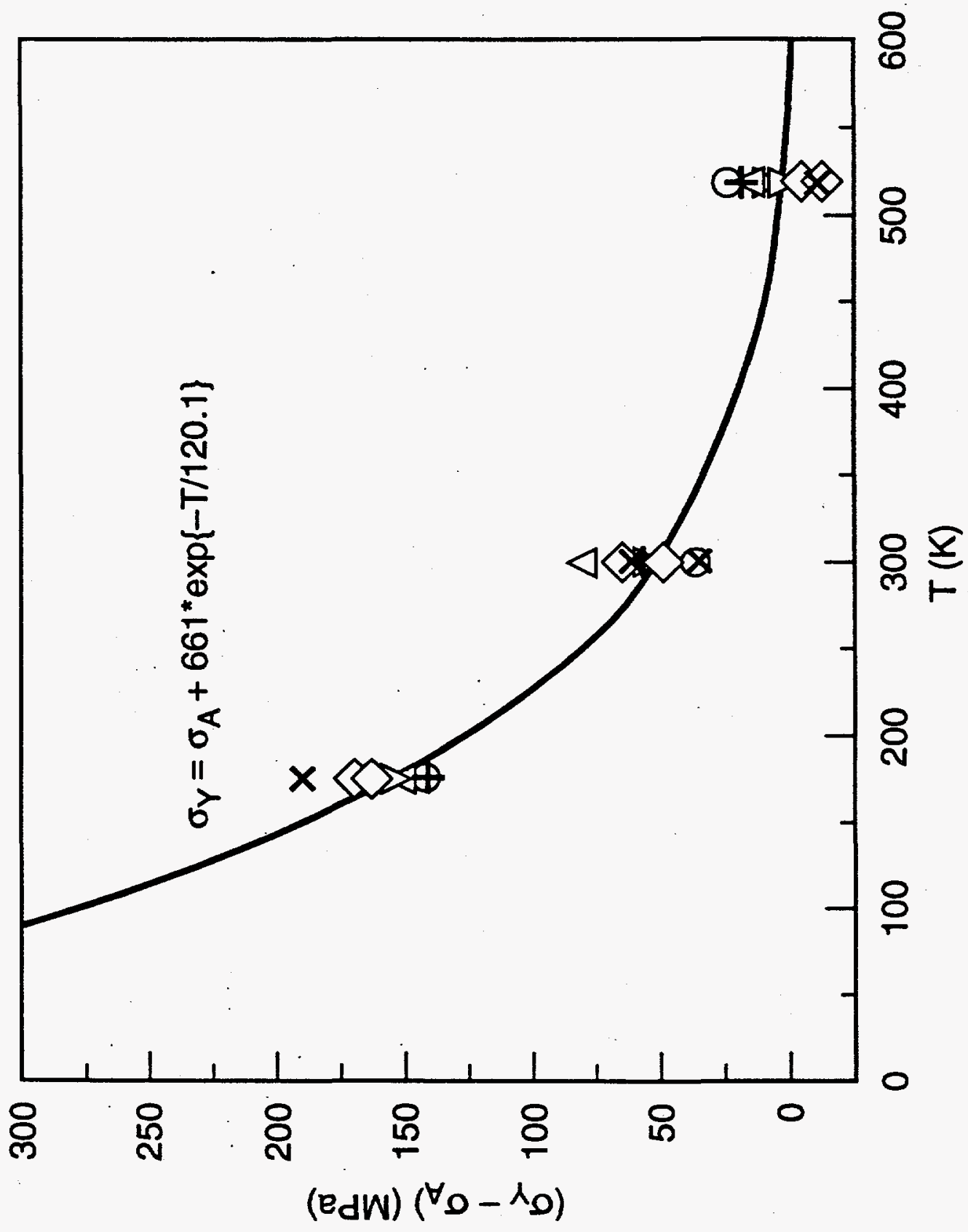

